\title{
Effect of Chemical Precursors On the Optical and Electrical Properties of p-Type Transparent Conducting $\mathrm{Cr}_{2} \mathrm{O}_{3}:(\mathrm{Mg}, \mathrm{N})$
}

\author{
Elisabetta Arca ${ }^{1 *}$, Karsten Fleischer $^{1}$, Sergey A. Krasnikov ${ }^{1}$, Igor Shvets ${ }^{1}$ \\ ${ }^{1}$ Cleaner energy laboratory, School of physics and CRANN, Trinity College Dublin, Dublin 2 \\ Ireland
}

*Corresponding author: earca@ @tcd.ie, phone number: +353 (0)1 8963649

\begin{abstract}
$\mathrm{Cr}_{2} \mathrm{O}_{3}:(\mathrm{Mg}, \mathrm{N})$ has been reported as a p-type transparent conducting oxide. In this contribution the effect of each precursor used for the deposition by spray-pyrolysis, will be explored and their role in determining the optical and electrical properties of $\mathrm{Cr}_{2} \mathrm{O}_{3}$ will be outlined. A correlation between the structural, electrical, and optical properties upon introducing nitrogen precursors has been established. In particular it has been shown that the presence of ammonium salts in the deposition environment results in less absorbing films. By combining optical measurements and NEXAFS studies, a mechanism is proposed to explain the change in the optical properties. Moreover, it is shown that the presence of the nitrate moiety in the reaction environment is necessary to improve the electrical conductivity of the deposited films. The reaction of the nitrate moiety with the ammonium moiety has been proposed as the mechanism to explain the boost in conductivity.
\end{abstract}

Keywords: defect-chemistry, p-type $\mathrm{TCO}, \mathrm{Cr}_{2} \mathrm{O}_{3}$, NEXAFS, spray pyrolysis 


\section{Introduction}

Chromium sesquioxide, $\left(\mathrm{Cr}_{2} \mathrm{O}_{3}\right)$, known also as chromia (mineral name Eskolaite), is an anti-ferromagnetic wide band gap insulator $\left(\mathrm{E}_{\mathrm{g}}=3.4 \mathrm{eV}\right)$ and it is the most stable oxide that chromium can form. It is a well-known refractory material used for its mechanical properties as it is among the hardest oxides. ${ }^{1}$ Recently $\mathrm{Cr}_{2} \mathrm{O}_{3}$ and $\mathrm{Cr}_{2} \mathrm{O}_{3}: \mathrm{N}$ have received attention for application in optoelectronic devices, in particular as hole transporting layer in organic solar cells. $^{2-5}$

$\mathrm{Cr}_{2} \mathrm{O}_{3}$ crystallizes in the corundum structure with hexagonal closed packed layers of oxygen atoms and two thirds of the octahedral sites filled with $\mathrm{Cr}$ atoms. ${ }^{6,7}$ Each octahedron shares one face and three edges with neighboring occupied octahedrons, with the metal cation slightly displaced from the geometric center of the octahedron. The latter effect and the fact that one third of the octahedrons are empty are advocated as causes of a slight difference in the $\mathrm{O}-\mathrm{O}$ distance 8,9 within the cell. The primitive cell is rhombohedral, the unit cell is hexagonal, with crystal parameters of $a=4.959 \AA$ and $c=13.594 \AA$.

Due to the octahedral field the $\mathrm{Cr} 3 \mathrm{~d}$ states are split into sub-bands: the triple degenerate $t_{2 g}$ and the double degenerate $e_{g}$. Understanding the energy position of these two bands and their relative contributions to the valence band maximum and conduction band minimum is strictly important to understand the optical and electrical properties of this material, in particular for its application in solar cells.

Regarding the optical properties, $\mathrm{Cr}_{2} \mathrm{O}_{3}$ band gap is reported to be $3.4 \mathrm{eV}$. Below the absorption edge, two other weak optical transitions are visible at $\sim 2$ and $\sim 2.6 \mathrm{eV}$ in almost any transmission spectra of $\mathrm{Cr}_{2} \mathrm{O}_{3}$ reported in literature, regardless of the growth technique. These bands are usually attributed to dipole forbidden, quadrupole allowed, d-d transition 
from occupied $t_{2 g}$ levels to unoccupied $e_{g}$ levels and are responsible for the distinctive green color of $\mathrm{Cr}_{2} \mathrm{O}_{3}$ powders. ${ }^{7,10}$

From the electrical point of view, $\mathrm{Cr}_{2} \mathrm{O}_{3}$ is usually reported as an insulator, with the possibility of low native p-type conductivity. ${ }^{4}$ Doping with $\mathrm{Mg}$ is well known to induce p-

type semiconductor behavior, ${ }^{11,12}$ however, Uekawa and Kaneko highlighted a simultaneous degradation of the optical properties due to an increase in the absorption coefficient upon doping with $\mathrm{Mg} .{ }^{12}$ The latter was attributed to the formation of $\mathrm{Cr}(\mathrm{VI})$ defects.

Recently we reported a method to improve both optical and electrical properties of $\mathrm{Cr}_{2} \mathrm{O}_{3}$ by co-doping with $\mathrm{Mg}$ and $\mathrm{N} .{ }^{13}$ In this way spray pyrolysis grown $\mathrm{Cr}_{2} \mathrm{O}_{3}$ was converted into a p-type transparent conducting oxide, showing semiconducting behaviour without compromising the optical transparency. In this contribution, we focus on the role of each precursor on achieving the desired properties. In particular the role of the nitrate, chloride and ammonium moiety as well as the role of the $\mathrm{pH}$ will be discussed in regards to their effect on the structural, optical and electrical properties of $\mathrm{Cr}_{2} \mathrm{O}_{3}$.

\section{Experimental details}

Depositions were carried out by spray pyrolysis, using a home-built set up. Details of the deposition chamber are reported elsewhere. ${ }^{14}$

All precursors were purchased from Sigma Aldrich and used without any further purification. Chromium nitrate and chromium chloride were used as chromium sources, ammonium acetate and ammonium chloride were used as nitrogen sources, magnesium chloride and acetate as magnesium sources. The $\mathrm{pH}$ of the solution was varied from 5 to 0 . Hydrochloric acid and nitric acid were used for this purpose. Four different sets of samples were grown: undoped $\mathrm{Cr}_{2} \mathrm{O}_{3}, \mathrm{Mg}$-doped $\mathrm{Cr}_{2} \mathrm{O}_{3}, \mathrm{~N}$-doped $\mathrm{Cr}_{2} \mathrm{O}_{3}$ and $(\mathrm{Mg}, \mathrm{N})$-co-doped $\mathrm{Cr}_{2} \mathrm{O}_{3}$, for which a variety of precursor combinations were investigated. All solutions had a 
chromium salt concentration of $0.1 \mathrm{M}$, ammonium salts of $0.4 \mathrm{M}$ and magnesium precursors of 0.011M. The solution was delivered at a rate of $1.7 \mathrm{ml} / \mathrm{min}$ and the deposition time was adjusted in the range of 800-1000 seconds, in order to achieve a comparable film thickness in the order of 150-250 $\mathrm{nm}$ for films grown with each precursor solution.

Glass slides (coverslip $0.17 \mathrm{~mm}$, Roth) were used as substrates and the deposition temperature measured at the surface was adjusted to be $430 \pm 10^{\circ} \mathrm{C}$.

Optical properties were characterized by UV-Visible spectrophotometry by using a Perkin Elmer 650S spectrophotometer equipped with an integrating sphere. Structural properties were analyzed by grazing incident X-ray diffraction (GIXD) using a Bruker D8 Discover. Analysis of the measured patterns was performed by using the Rietveld method implemented

in the MAUD software. ${ }^{15}$ Information on the crystallographic parameters and crystallite size could thus be extracted. Resistivity and carrier activation energies were determined from sheet resistance measurements, performed in a four point probe linear geometry configuration at a temperature range from $50-150^{\circ} \mathrm{C}$. The film thickness was determined by cross-sectional scanning electron microscope (SEM) by using the Zeiss Ultra Plus - Scanning Electron Microscope. Near edge X-Ray absorption fine structure (NEXAFS) measurements were performed at beam line I511-3 of the MAX-lab National Laboratory, Sweden. The O 1s NEXAFS spectra were recorded in the total fluorescence yield mode using a multichannel plate detector. The photon energy resolution was set to $100 \mathrm{meV}$.

\section{Results and discussion}

\subsection{Crystallographic and optical properties}

In the first set of samples, undoped, $\mathrm{N}$-only and $\mathrm{Mg}$-only doped, as well as $\mathrm{Mg}, \mathrm{N}$ codoped films were grown by using chromium nitrate, ammonium acetate and magnesium chloride at $\mathrm{pH}=0(\mathrm{HCl})$. All films show only one phase, (Eskolaite, PDF 01-072-3533). In 
symmetric scans no significant difference could be seen between samples, most likely due to the poor signal to noise ratio at high angles. However, in grazing incidence configuration, more information could be gathered due to a better signal to noise at higher angles and substantial shifts of the peaks for N-doped samples were observed (see Figure 1).

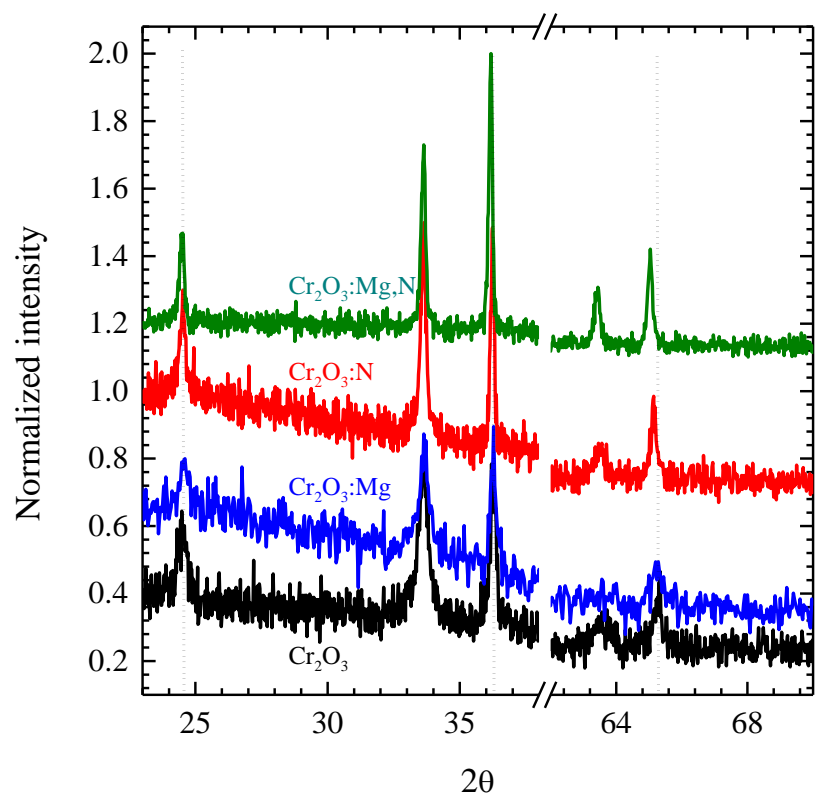

Figure 1. Grazing incidence X-ray diffraction of (-) undoped, (-) Mg-doped, (-) N-doped and (-) $(\mathrm{Mg}, \mathrm{N})$-codoped $\mathrm{Cr}_{2} \mathrm{O}_{3}$. The vertical dotted lines indicate the database positions and are used as guide to the eyes. Samples shown have been grown using $\mathrm{Cr}\left(\mathrm{NO}_{3}\right)_{3}, \mathrm{MgCl}_{2}$, and ammonium acetate in different combinations.

As it can been seen from Figure 1, there is a shift in the peak position to lower diffraction angles for samples grown by using ammonium salts in solution. The Rietveld method was used to determine the lattice constants, the dimension of the coherent diffraction domains and the micro strain values. More specifically, diffraction domains were considered isotropic and their dimensions and the micro strain were determined by using the so called "Delf" model implemented in the program MAUD. The latter allows the samples contribution to the broadening of the peak (integral breadth) due to the micro strain and due to the crystal size to be discerned, owing to their different angular dependence: $\tan \Theta$ dependence for the micro strain versus $1 / \cos \Theta$ dependence for the crystal size. This implies that the instrumental 
contribution to the peak broadening has been previously estimated (Cagliotti formula) and it is taken into account during the fitting routine. The following trends have been observed:

- $\quad$ The value of the $c$ lattice constant remains unchanged, within the experimental error, for all samples: $13.582 \pm 0.006 \AA$.

- samples where $\mathrm{CrCl}_{3}$ was used as $\mathrm{Cr}$ source show an $a$-lattice constant systematically larger than those where the nitrate precursor was used: for example, undoped samples grown out of the chloride precursor have an average lattice constant of $4.959 \AA$, which is in line with the database value and larger than that typical of undoped samples grown out of the nitrate source, whose average value is $4.949 \AA$. The same trend is observed for doped samples (see Figure 2)

- all samples where ammonium ions were present in solution show bigger diffraction domains (from $300 \AA$ for undoped samples up to $700 \AA$ for $\mathrm{Mg}, \mathrm{N}$ codoped samples, see Figure 2)

- all samples where ammonium ions were present in the solution have a larger $a$-lattice constant than undoped or only Mg doped samples (4.949 $\AA$ for undoped or only Mg-doped sample vs $4.955 \AA$ for only N-doped samples and $4.964 \AA$ for $\mathrm{Mg}, \mathrm{N}$ co-doped samples, see Figure 2)

- a correlation between the $a$ lattice parameter and the crystallite size could be determined, however, the trend is the opposite to the one expected from size confinement effects and no corresponding correlation in the c-axis has been observed (see Figure 2) 


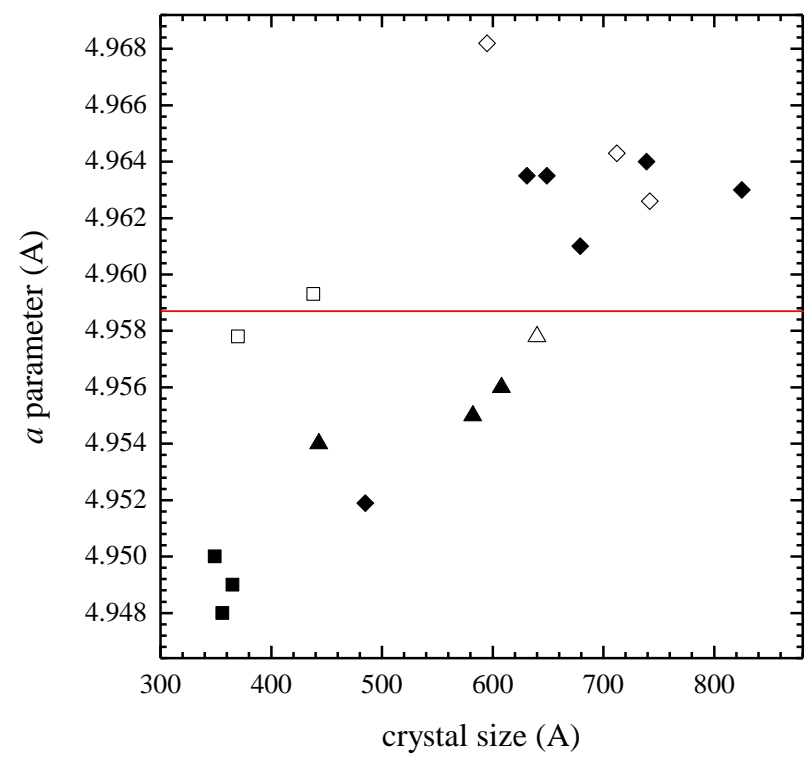

Figure 2. a-parameter as a function of crystallite size. Hollow symbols denote samples grown using chromium chloride; full symbols are for chromium nitrate. Squared symbols denote undoped samples; triangular symbols are for N-only doped samples; rhombohedral symbols are for $\mathrm{Mg}, \mathrm{N}$-codoped samples.

According to the Rietveld refinement, introducing ammonium ions in the precursor solution leads to the larger crystallite size. In other words the presence of ammonium ions in the reaction environment helps to improve the crystal quality of the material deposited by increasing the crystal size. However the latter cannot be responsible for the increase in the crystal cell parameter $a$, since the opposite trend is expected from crystal size effects. Another possible reason for such lattice expansion can be stoichiometric differences in the $\mathrm{Cr}_{2} \mathrm{O}_{3}$ structure. A possible explanation is the subtle change in $\mathrm{Cr} / \mathrm{O}$ stoichiometry in the ammonium rich atmospheres. As it will be outlined in the NEXAFS studies, the oxygen $1 \mathrm{~s}$ edge shows a peak attributed to the $\mathrm{CrO}_{3}$ phase. Such phase cannot be detected in the GIXD patterns, which means that, from a quantitative point of view, this parasitic phase is below the detection limit, or, most likely, it is only present as a local disorder of the bond arrangement.

Another possible explanation is the incorporation of nitrogen. According to literature the Cr-N bond (2.06 $)$ is longer than the $\mathrm{Cr}-\mathrm{O}$ bond $(2.01$ and $1.96 \AA),{ }^{16}$ which could lead to the 
observed lattice expansion, however this latter hypothesis is rather speculative as, at present, there is no direct evidence for incorporation of $\mathrm{N}$ into the crystal structure of $\mathrm{Cr}_{2} \mathrm{O}_{3}$. To fully assess the issue, direct bulk measurement of $\mathrm{N}$ concentration and DFT calculation on the effect of nitrogen on $\mathrm{Cr}_{2} \mathrm{O}_{3}$ would be required. Determination of the $\mathrm{N}$ content by XPS is currently not feasible for two reasons. First of all, this technique is surface sensitive, thus giving only the amount of nitrogen incorporated in the first few nanometers of the samples rather than the bulk quantity. Secondly, the sputtering procedure, required to remove potential contaminants from the surface prior to the XPS measurements, interferes with the $\mathrm{N}$-determination by inducing the molecular nitrogen absorbed on the surfaces to react and bond to uncoordinated $\mathrm{Cr}$ atoms, thus making impossible to distinguish between incorporated nitrogen and reacted surface adsorbed nitrogen. NEXAFS represents an alternative technique to detect the presence of nitrogen, especially because it is bulk-sensitive and it allows discriminating the chemical status of nitrogen $\left(\mathrm{N}_{2}\right.$ vs. $\mathrm{NO}_{\mathrm{x}}$ for example). $\mathrm{N}$ K-edge NEXAFS was performed; however the studies were not conclusive. In fact, as it can be seen in Figure 3, samples are quite porous, thus the main signal detected was a sharp molecular nitrogen peak, caused by surface adsorbed or trapped $\mathrm{N}_{2}$. The second problem arose from an unusual high background signal at that particular energy range for any $\mathrm{Mg}$ doped samples. Due to these instrumental and noise limitations, we were not able to detect incorporated nitrogen reliably. We can however estimate an upper limit of the incorporated nitrogen of $n_{N}<1 \times 10^{19}$ $\mathrm{cm}^{-3}$. Further experiments involving in-situ heating cycles to remove adsorbed and trapped nitrogen would be required to quantify the nitrogen with NEXAFS.

The second main consequence of the presence of ammonium precursors in solution is a reduction in the optical absorption coefficient. In order to study this effect, integrated transmission measurements were performed and the thickness of each sample was determined by cross-sectional SEM (Figure 3). In this way, the absorption coefficient $(\alpha)$ could be 
calculated. For the thickness determination, a thin slab of each sample was cut and secured to the SEM sample holder. Several SEM images, similar to the one shown in Figure 3, were taken for each slab and the thickness of the deposited films was determined as the average over the entire dataset. 3 different nitrogen concentrations were taken into consideration ([N] equal to $0,0.3$ and $0.5 \mathrm{M}$ ), for each of which, several samples were grown and analyzed. The error bars in Figure 4 have been determined from the statistical variance among the samples grown at a given nitrogen concentration in the solution. A Tauc plot was used to determine the band gaps. A systematic decrease in the absorption coefficient (Figure 4) and a band gap opening (Figure 5) is visible for all the samples grown with ammonium salts in solution.

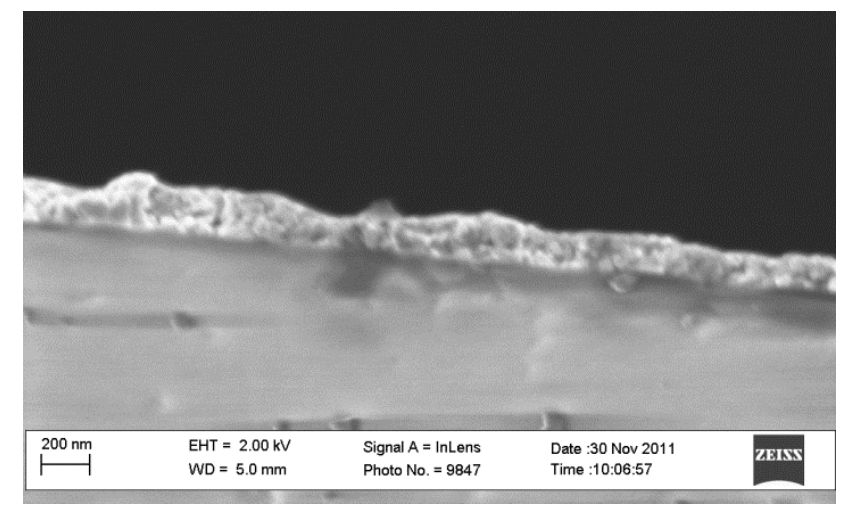

Figure 3. SEM cross section of a $\mathrm{Cr}_{2} \mathrm{O}_{3}$ sample doped with nitrogen. The average sample thickness was determined by measuring the height of the film at different points of the sample. 


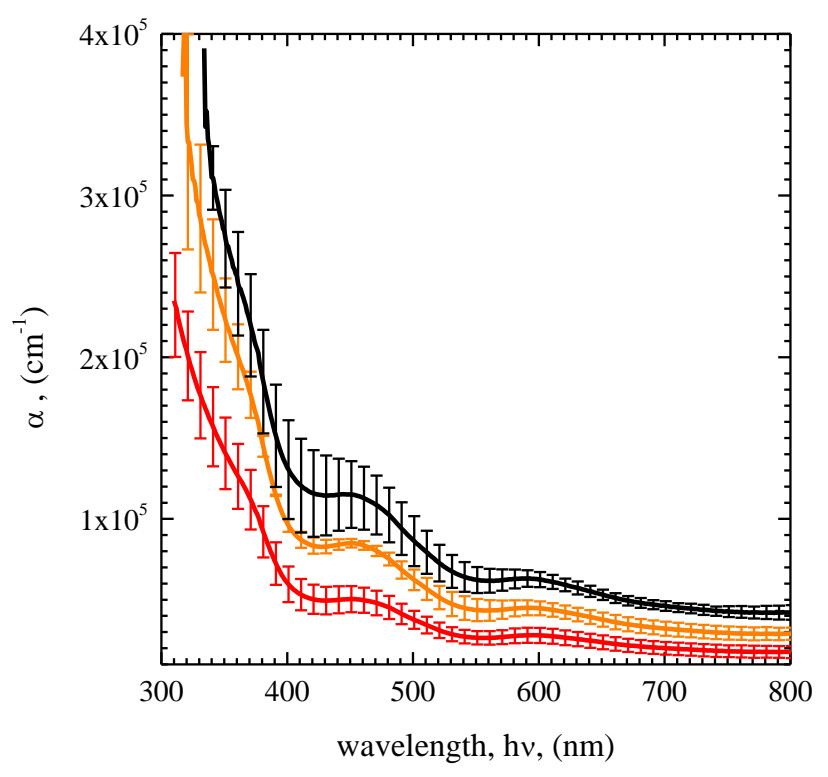

Figure 4. Absorption coefficient as determined from combining integrated transmission measurements and thickness determination via cross-sectional SEM for (-) undoped $\mathrm{Cr}_{2} \mathrm{O}_{3}$, (-) N-doped $\mathrm{Cr}_{2} \mathrm{O}_{3}$ solution ratio 1:3, (-) N-doped $\mathrm{Cr}_{2} \mathrm{O}_{3}$ solution ratio 1:5. The error bars originate from the standard deviation of the SEM thickness measurement and variations between similar samples.

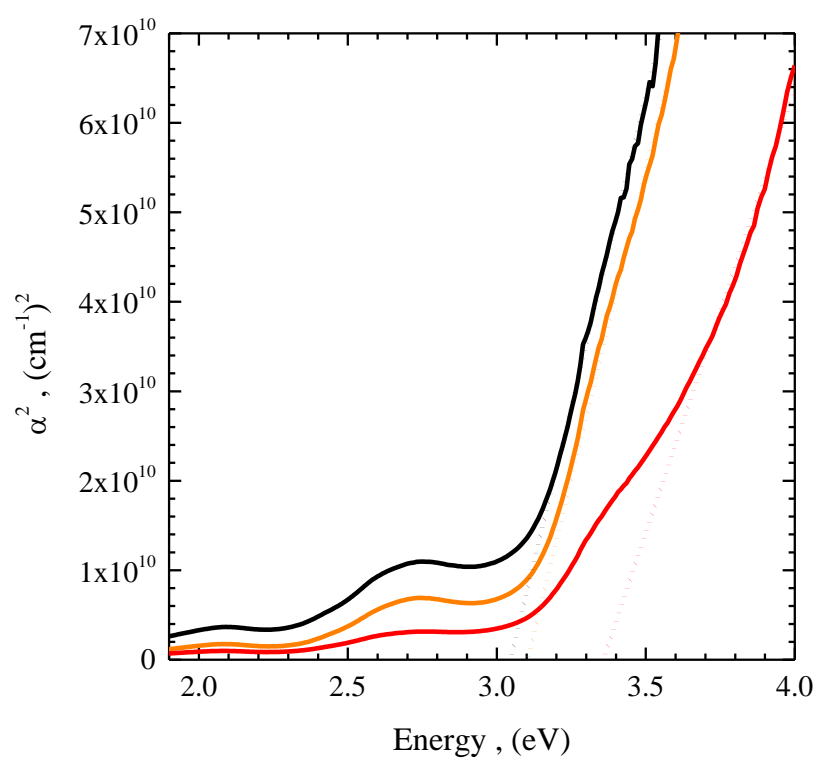

Figure 5. Band gap determination of (-) undoped $\mathrm{Cr}_{2} \mathrm{O}_{3}$, (-) $\mathrm{N}$-doped $\mathrm{Cr}_{2} \mathrm{O}_{3}$ solution ratio 1:3, (-) $\mathrm{N}$-doped $\mathrm{Cr}_{2} \mathrm{O}_{3}$ solution ratio of 1:5. The linear portions of the curves that were used for the fitting were chosen in order to minimize the R-factor. 
In order to assess the origin of this change, NEXAFS has been conducted on undoped, Mg-only and $\mathrm{N}$-only doped and $\mathrm{Mg}-\mathrm{N}$-codoped samples all grown using the chromium nitrate precursor, $\mathrm{MgCl}_{2}$ and $\mathrm{NH}_{4} \mathrm{CH}_{3} \mathrm{CO}_{2}$ as doping sources.
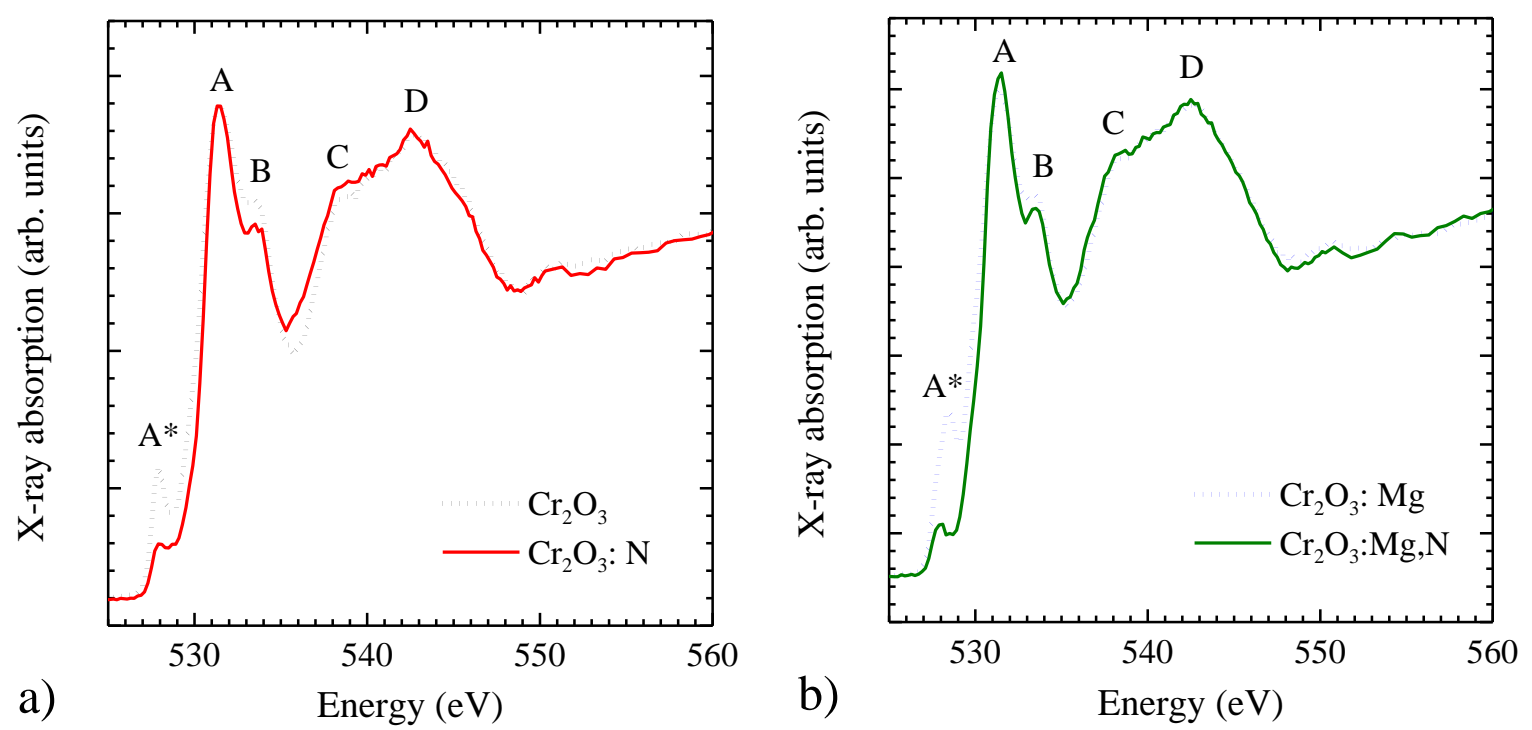

Figure 6. Near edge X-ray absorption spectra of the oxygen 1 s absorption. a) compares the data from undoped $\mathrm{Cr}_{2} \mathrm{O}_{3}$ with (-) and without (-.) ammonium salts in the solution, while b) shows the spectra of $\mathrm{Mg}$ doped $\mathrm{Cr}_{2} \mathrm{O}_{3}$ with (-) and without (--.) ammonium salts. The energy positions and relative intensities of the structures $A-D$ are typical for $\mathrm{Cr}_{2} \mathrm{O}_{3}$. The energy position of the defect structure $A^{*}$ at $528.0 \mathrm{eV}$ is consistent with a local bond arrangement of $\mathrm{CrO}_{3}$. Note that in samples grown with ammonium acetate, the intensity of this structure is reduced.

The $\mathrm{O}$ 1s NEXAFS spectra for the samples under study are shown in Figure 6. The relative intensities of the spectra are normalized to the same continuum jump at the photon energy of $565 \mathrm{eV}$. Examining the series of the O 1s NEXAFS spectra in Figure 6 one can see that the spectra are quite similar and consist of five prominent absorption structures $\left(\mathrm{A}^{*}, \mathrm{~A}\right.$, $\mathrm{B}, \mathrm{C}$ and $\mathrm{D})$ resulting from the $\mathrm{O} 1 \mathrm{~s}-2 \mathrm{p}$ transitions. The energy positions and relative intensities of the structures A-D are typical for O 1s NEXAFS spectra measured in previous studies from polycrystalline $\mathrm{Cr}_{2} \mathrm{O}_{3}$ powder, an $\alpha-\mathrm{Cr}_{2} \mathrm{O}_{3}$ (11 102$)$ single crystal and thin (40 nm) $\mathrm{Cr}_{2} \mathrm{O}_{3}$ films grown on the $\mathrm{Al}_{2} \mathrm{O}_{3}(0001) .{ }^{17,18}$ The structures A-D do not exhibit any significant changes, while the intensity of the structure $A^{*}$, present in the samples grown by 
spray pyrolysis, is significantly reduced anytime that ammonium salt was present in the solution. The energy position of the structure $A^{*}$ in Figure 6 is $528.0 \mathrm{eV}$ and corresponds to the main absorption peak in the $\mathrm{O}$ 1s NEXAFS spectrum measured from polycrystalline $\mathrm{CrO}_{3}$ powder. ${ }^{17}$ As previously said, this phase is not visible in the XRD patterns, which means that, quantitatively, this is below the XRD detection limit, or it is only present in local bond arrangements. The presence of $\mathrm{Cr}(\mathrm{VI})$ has been advocated by Kaneco and Uekawa ${ }^{12}$ as the cause of the brown discoloration appearing in their $\mathrm{Mg}$-doped $\mathrm{Cr}_{2} \mathrm{O}_{3}$ films. From the microscopic point of view, both our undoped and $\mathrm{Mg}$-doped films present a strong brown discoloration, which tends to disappear as soon as ammonium salts are introduced in the precursors' solutions. Only N-doped films have a green colour again, while co-doped films have a much attenuated brown colour. These observations and the NEXAFS data link the presence of a brown tint to the presence of $\mathrm{Cr}(\mathrm{VI})$ ions, thus confirming the data reported by Kaneco and Uekawa. ${ }^{12}$ As a further step, it has been proven that the formation of this defect can be prevented, or at least strongly reduced, by the presence of the ammonium moiety or its decomposition products in the reaction atmosphere.

\subsection{Electrical properties}

In its perfectly stoichiometric form, $\mathrm{Cr}_{2} \mathrm{O}_{3}$ is an insulator. Our spray-pyrolysis grown films, however, show a very low, yet measurable, conductivity, even for the undoped material, with the worst properties obtained for samples grown by using the chloride precursor (see Table 1). Films grown by using the nitrate precursors show a lower resistivity and a smaller $a$-axis than those deposited with the chloride precursor.

$\mathrm{Mg}$ is a well-known dopant for $\mathrm{Cr}_{2} \mathrm{O}_{3}$, able to provide a hole if placed substitutionally on a Cr site $\left(\mathrm{Mg}_{\mathrm{Cr}}\right)$ due to the different oxidation states $(\mathrm{Mg}(+\mathrm{II})$ versus $\mathrm{Cr}(+\mathrm{III}))$. Improved 
electrical properties were obtained by co-doping. For the $(\mathrm{Mg}, \mathrm{N})$-co-doped samples different conditions were tested by adjusting the $\mathrm{pH}$. Starting with chromium nitrate $(0.1 \mathrm{M})$ and ammonium acetate $(0.4 \mathrm{M})$ as precursors, the $\mathrm{pH}$ of the solution was 5 . By adding $\mathrm{HCl}$, the $\mathrm{pH}$ was brought down in steps to a value of 0 . Samples have been grown with these different precursor solutions and sheet resistance, activation energy and thickness were determined for each one. Activation energies were determined by means of Arrhenius plots.
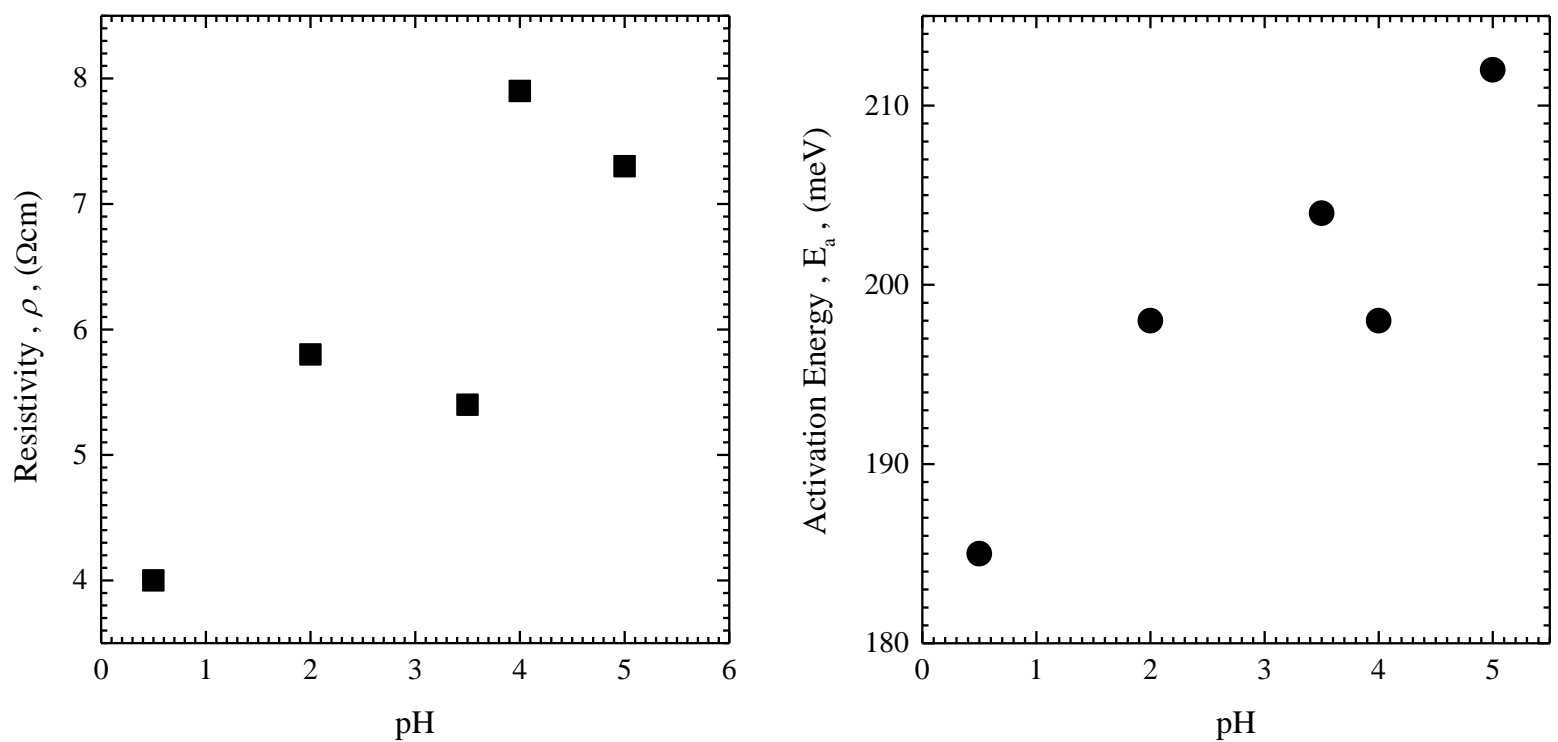

Figure 7. Resistivity measurements (ロ) and activation energy (•) of $\mathrm{Cr}_{2} \mathrm{O}_{3}: \mathrm{Mg}, \mathrm{N}$ as a function of $\mathrm{pH}$ for a solution which contains chromium nitrate, ammonium acetate and $\mathrm{MgCl}_{2}$ as precursors. A clear trend is visible: the lower the $\mathrm{pH}$ of the original precursor solution, the lower the resistivity and the activation energy for the carriers in the final sample.

As it can be seen in Figure 7, the resistivity decreases as the $\mathrm{pH}$ goes down. At the same time also the effective carrier activation energy decreases. From the chemical point of view, lowering the $\mathrm{pH}$ can have two main consequences:

- partial or complete removal of the acetate moiety, by protonation and release of the same as acetic acid

- promoting the reaction between nitrate and ammonium by favoring the reduction of the nitrate moiety 
In order to test if the acetate moiety was interfering with the reaction, samples were grown by using $\mathrm{NH}_{4} \mathrm{Cl}$ and $\mathrm{Cr}\left(\mathrm{NO}_{3}\right)_{3}$ as $\mathrm{N}$ and $\mathrm{Cr}$ sources respectively, in other words, no acetate was present in the solution. The $\mathrm{pH}$ of the starting solution was 3 , which was brought down to 0 by adding $\mathrm{HCl}$. As it can be seen from Table 1, samples grown at $\mathrm{pH} 0$ using ammonium chloride have a comparable resistivity to that of the samples grown by using ammonium acetate, while the sample grown at a $\mathrm{pH}$ of 3 has a higher resistance than those grown at a $\mathrm{pH}$ 0. The fact that the same trend with $\mathrm{pH}$ was observed when ammonium chloride was used leads to the conclusion that the effect of the $\mathrm{pH}$ is not related to the removal of acetate from the solution but has to be linked to the decomposition pathway followed by the nitrate moiety at different pHs. It is well known that heating of ammonium nitrate solution under atmospheric pressure is followed by the decomposition of the nitrate moiety by ammonium ions in acidic environment (or ammonia in basic condition), producing $\mathrm{N}_{2}$ and water as final products.

$$
\mathrm{NH}_{4}^{+}+3 \mathrm{NO}_{3}^{-} \rightarrow 4 \mathrm{~N}_{2}+2 \mathrm{H}^{+}+9 \mathrm{H}_{2} \mathrm{O}
$$

Ammonia is a better reducing agent under acidic conditions, when it acts as ammonium ions. ${ }^{19,20}$ The final products of the decomposition vary depending on the temperature and pressure at which the reaction is conducted. High temperature, pressure and acidic $\mathrm{pH}$ favor this reaction. ${ }^{19,20}$ Nitrous oxides are for sure developed during this decomposition process, and in certain circumstances they are the major final product of the reaction. For example, it was demonstrated that under pressurized conditions and at $180^{\circ} \mathrm{C}, \mathrm{NH}_{4} \mathrm{NO}_{3}$ decomposes giving nitrous oxide and nitrogen with a ratio of $4: 1$. The content of nitrous oxide was increased as the $\mathrm{pH}$ was lowered. Despite the fact that in our case the reaction was conducted at atmospheric pressure, it is reasonable to assume that the reaction between the nitrate and the ammonium ions does occur producing highly reactive species such as $\mathrm{NO}$ and $\mathrm{NO}_{2}$, whose production is favored at low pHs. At the same time $\mathrm{NO}$ and $\mathrm{NO}_{2}$ have been reported to 
be of significant importance for the development of p-type materials, in particular when this is to be performed by $\mathrm{N}$-doping. ${ }^{21}$

The nitrate decomposition is therefore a key factor in achieving good electrical properties in the grown film. In order to confirm this, additional experiments have been carried out. In the first place, the deposition has been carried out by employing $\mathrm{CrCl}_{3}$ rather than $\mathrm{Cr}\left(\mathrm{NO}_{3}\right)_{3}$. All other parameter were kept unchanged. The $\mathrm{pH}$ was adjusted to be zero by adding $\mathrm{HCl}$. As it can be noticed in Table 1, higher resistivities were observed when only chloride and acetate were used, i.e. no nitrate present in the solution (line 7). In this case higher activation energies were registered as well (for films grown in the presence of nitrate $E_{a}=195 \pm 10 \mathrm{meV}$, in the absence of nitrate $240 \pm 10 \mathrm{meV}$ ). Following this, the nitrate moiety was introduced by using $\mathrm{HNO}_{3}$ rather than $\mathrm{HCl}$ to adjust the $\mathrm{pH}$, and again using $\mathrm{CrCl}_{3}, \mathrm{MgCl}_{2}$ and ammonium acetate as $\mathrm{Cr}, \mathrm{Mg}$ and $\mathrm{N}$ precursors respectively. In this case, resistivities in line with the best performing samples (Table 1 line 4 and 8 ) were achieved. Similar results were obtained when $\mathrm{Cr}\left(\mathrm{NO}_{3}\right)_{3}$ and $\mathrm{HNO}_{3}$ were used for the deposition. These experiments confirm that the presence of nitrate in solution and its decomposition are necessary in order to achieve the highest conductivity.

Fanning et $\mathrm{al}^{20}$ reported that the presence of chloride ions was crucial for the development of the NO as final product of the decomposition reaction. In order to verify this point we deposited $\mathrm{Cr}_{2} \mathrm{O}_{3}:(\mathrm{Mg}, \mathrm{N})$ by using only nitrate and acetate salts. Nitric acid was used to adjust the $\mathrm{pH}$. In this case only a slightly higher resistivity is observed. This is an indication, that chloride plays a secondary role in the proposed decomposition mechanism.

Analysis of the transport mechanism is currently undergoing. Preliminary studies performed on both spray pyrolysis grown polycrystalline films and epitaxial grown PLD films, highlight that the poor morphological structure and the high concentration of defects are limiting the electrical properties of the films deposited by spray pyrolysis, in other words 
the activation energy reported in the present contribution are not a pure measurement of the acceptor level and a strong contribution from grain boundaries and defects is expected to limit the conductivity of these films. Therefore, it can be anticipated that better electrical properties can be achieved by improving the morphology and crystal quality of the films.

Table 1. List of precursor combinations and resistivity values. The case where no nitrate moiety was present in solution is highlighted in red. As it can be seen, a much higher resistivity was observed in this case, confirming the crucial role of $\mathrm{NO}_{3}^{-}$for the electrical properties.

\begin{tabular}{|c|c|c|c|c|c|c|}
\hline & Sample & Cr source & Mg source & N source & pH & $\rho,(\Omega \mathrm{cm})$ \\
\hline 1 & $\mathrm{Cr}_{2} \mathrm{O}_{3}$ & $\mathrm{Cr}\left(\mathrm{NO}_{3}\right)_{3}$ & none & none & & $>1000$ \\
\hline 2 & $\mathrm{Cr}_{2} \mathrm{O}_{3}$ & $\mathrm{CrCl}_{3} \cdot 6 \mathrm{H}_{2} \mathrm{O}$ & none & none & & 400 \\
\hline 3 & $\mathrm{Cr}_{2} \mathrm{O}_{3}(\mathrm{Mg}, \mathrm{N})$ & $\mathrm{Cr}\left(\mathrm{NO}_{3}\right)_{3}$ & $\mathrm{MgCl}_{2}$ & $\mathrm{NH}_{4}\left(\mathrm{CH}_{3} \mathrm{CO}_{2}\right)_{2}$ & $0, \mathrm{HCl}$ & 4.0 \\
\hline 4 & $\mathrm{Cr}_{2} \mathrm{O}_{3}(\mathrm{Mg}, \mathrm{N})$ & $\mathrm{Cr}\left(\mathrm{NO}_{3}\right)_{3}$ & $\mathrm{MgCl}_{2}$ & $\mathrm{NH}_{4}\left(\mathrm{CH}_{3} \mathrm{CO}_{2}\right)_{2}$ & $3, \mathrm{HCl}$ & 5.4 \\
\hline 5 & $\mathrm{Cr}_{2} \mathrm{O}_{3}(\mathrm{Mg}, \mathrm{N})$ & $\mathrm{Cr}\left(\mathrm{NO}_{3}\right)_{3}$ & $\mathrm{MgCl}_{2}$ & $\mathrm{NH}_{4} \mathrm{Cl}$ & $0, \mathrm{HCl}$ & 4.9 \\
\hline 6 & $\mathrm{Cr}_{2} \mathrm{O}_{3}(\mathrm{Mg}, \mathrm{N})$ & $\mathrm{Cr}\left(\mathrm{NO}_{3}\right)_{3}$ & $\mathrm{MgCl}_{2}$ & $\mathrm{NH}_{4} \mathrm{Cl}$ & $3, \mathrm{HCl}$ & 6.0 \\
\hline 7 & $\mathrm{Cr}_{2} \mathrm{O}_{3}(\mathrm{Mg}, \mathrm{N})$ & $\mathrm{CrCl}_{3} \cdot 6 \mathrm{H}_{2} \mathrm{O}$ & $\mathrm{MgCl}_{2}$ & $\mathrm{NH}_{4}\left(\mathrm{CH}_{3} \mathrm{CO}_{2}\right)_{2}$ & $\mathrm{O}, \mathrm{HCl}$ & 40 \\
\hline 8 & $\mathrm{Cr}_{2} \mathrm{O}_{3}(\mathrm{Mg}, \mathrm{N})$ & $\mathrm{CrCl}_{3} \cdot 6 \mathrm{H}_{2} \mathrm{O}$ & $\mathrm{MgCl}_{2}$ & $\mathrm{NH}_{4}\left(\mathrm{CH}_{3} \mathrm{CO}_{2}\right)_{2}$ & $0, \mathrm{HNO}_{3}$ & 9 \\
\hline 9 & $\mathrm{Cr}_{2} \mathrm{O}_{3}(\mathrm{Mg}, \mathrm{N})$ & $\mathrm{Cr}\left(\mathrm{NO}_{3}\right)_{3}$ & $\mathrm{MgCl}_{2}$ & $\mathrm{NH}_{4}\left(\mathrm{CH}_{3} \mathrm{CO}_{2}\right)_{2}$ & $0, \mathrm{HNO}_{3}$ & 7 \\
\hline 10 & $\mathrm{Cr}_{2} \mathrm{O}_{3}(\mathrm{Mg}, \mathrm{N})$ & $\mathrm{Cr}\left(\mathrm{NO}_{3}\right)_{3}$ & $\mathrm{Mg}\left(\mathrm{CH}_{3} \mathrm{CO}_{2}\right)_{2}$ & $\mathrm{NH}_{4}\left(\mathrm{CH}_{3} \mathrm{CO}_{2}\right)_{2}$ & $0, \mathrm{HCl}$ & 5.5 \\
\hline 11 & $\mathrm{Cr}_{2} \mathrm{O}_{3}(\mathrm{Mg}, \mathrm{N})$ & $\mathrm{Cr}\left(\mathrm{NO}_{3}\right)_{3}$ & $\mathrm{Mg}\left(\mathrm{CH}_{3} \mathrm{CO}_{2}\right)_{2}$ & $\mathrm{NH}_{4}\left(\mathrm{CH}_{3} \mathrm{CO}_{2}\right)_{2}$ & $0, \mathrm{HNO}_{3}$ & 9 \\
\hline
\end{tabular}

\section{Conclusion}

The role of the defect chemistry on the structural, optical and electrical properties of $\mathrm{Cr}_{2} \mathrm{O}_{3}:(\mathrm{Mg}, \mathrm{N})$ has been investigated.

Regarding the structural and optical properties, a systematic decrease in the absorption coefficient, an increase in the band gap and an increase in the $a$-crystal cell parameter was observed in conjunction with the presence of ammonium acetate in the precursor solution. Regarding the optical properties, this study confirms the role of $\mathrm{N}$ in improving the optical transparency and opening the band gap as previously reported for sputter deposited films ${ }^{2}$. Our NEXAFS experiments suggest that the ammonium precursors (or its decomposition 
products) are preventing the formation of a parasitic defect, $\mathrm{Cr}(\mathrm{VI})$, which was previously attributed to be responsible for the brown discoloration of $\mathrm{Cr}_{2} \mathrm{O}_{3}$ films ${ }^{12}$.

Regarding the defect chemistry, good electrical conductivity could only be found in samples where the nitrate moiety was present. If no nitrate was present in the solution, optical properties of the film were not altered, but a much worse conductivity was achieved. In order to prove that the nitrate was necessary, different combination of precursors have been tested, showing that as long as the $\mathrm{NO}_{3}^{-}$moiety was present in any form, good electrical performance was achieved. We also studied the role of the $\mathrm{pH}$, finding that at lower $\mathrm{pH}$, better conductivity and lower activation energies could be achieved. These two effects are explained as the lower $\mathrm{pH}$ favors the reaction of nitrate decomposition and the evolution of nitrogen oxide species (NO, $\mathrm{NO}_{2}$ etc.) at least as intermediate species, which are well known to help achieving p-type conductivity in oxides. No difference in the electrical properties was found upon using either ammonium acetate or ammonium chloride as nitrogen sources, meaning that only the ammonium-cation is involved in the reaction with the nitrate moiety. Chloride ions play a role comparable to that of $\mathrm{pH}$, i.e. their presence is beneficial to promote the decomposition reaction between the nitrate and the ammonium moiety.

\section{Acknowledgments}

National Development Plan (NDP) and Science Foundation Ireland are gratefully acknowledged for the financial support.

1. Tabbal, M.; Kahwaji, S.; Christidis, T. C.; Nsouli, B.; Zahraman, K., Pulsed Laser Deposition of Nanostructured Dichromium Trioxide Thin Films. Thin Solid Films 2006, 515, 1976-1984. 
2. Qin, P.; Fang, G.; He, Q.; Sun, N.; Fan, X.; Zheng, Q.; Chen, F.; Wan, J.; Zhao, X., Nitrogen Doped Amorphous Chromium Oxide: Stability Improvement and Application for the Hole-Transporting Layer of Organic Solar Cells. Sol. Energ. Mat. Sol. Cells 2011, 95, $1005-1010$

3. Qin, P.; Fang, G.; Sun, N.; Fan, X.; Zheng, Q.; Chen, F.; Wan, J.; Zhao, X., Organic Solar Cells with P-Type Amorphous Chromium Oxide Thin Film as Hole-Transporting Layer. Thin Solid Films 2011, 519, 4334-4341.

4. Cao, H.; Qiu, X.; Liang, Y.; Zhao, M.; Zhu, Q., Sol-Gel Synthesis and Photoluminescence of P-Type Semiconductor $\mathrm{Cr}_{2} \mathrm{O}_{3}$ Nanowires. Appl Phys Lett 2006, 88, 241112.

5. Choi, S.-Y.; Kim, M.-H.; Kwon, Y.-U., Effects of $\mathrm{Cr}_{2} \mathrm{O}_{3}$ Modification on the Performance of $\mathrm{SnO}_{2}$ Electrodes in Dsscs. Physical Chemistry Chemical Physics 2012, 14, $3576-3582$.

6. Catti, M.; Sandrone, G.; Valerio, G.; Dovesi, R., Electronic, Magnetic and Crystal Structure of $\mathrm{Cr}_{2} \mathrm{O}_{3}$ by Theoretical Methods. J. Phys. Chem. Solids 1996, 57, 1735-1741.

7. Zimmermann, R.; Steiner, P.; Hüfner, S., Electron Spectroscopies and Partial Excitation Spectra in $\mathrm{Cr}_{2} \mathrm{O}_{3}$. Journal of Electron Spectroscopy and Related Phenomena 1996, $78,49-52$.

8. Dera, P.; Lavina, B.; Meng, Y.; Prakapenka, V. B., Structural and Electronic Evolution of $\mathrm{Cr}_{2} \mathrm{O}_{3}$ on Compression to 55gpa. Journal of Solid State Chemistry 2011, 184, 3040-3049.

9. Mejias, J. A.; Staemmler, V.; Freund, H. J., Electronic States of the $\mathrm{Cr}_{2} \mathrm{O}_{3}(0001)$ Surface from Ab Initio Embedded Cluster Calculations. Journal of Physics: Condensed Matter 1999, 11, 7881. 
10. Chambers, S. A.; Williams, J. R.; Henderson, M. A.; Joly, A. G.; Varela, M.;

Pennycook, S. J., Structure, Band Offsets and Photochemistry at Epitaxial $\alpha-\mathrm{Cr}_{2} \mathrm{O}_{3} / \alpha-\mathrm{Fe}_{2} \mathrm{O}_{3}$ Heterojunctions. Surface Science 2005, 587, L197-L207.

11. Holt, A.; Kofstad, P., Electrical Conductivity and Defect Structure of Mg-Doped $\mathrm{Cr}_{2} \mathrm{O}_{3}$. Solid State Ionics 1997, 100, 201-209.

12. Uekawa, N.; Kaneko, K., Dopant Reduction in P-Type Oxide Films Upon Oxygen Absorption. The Journal of Physical Chemistry 1996, 100, 4193-4198.

13. Arca, E.; Fleischer, K.; Shvets, I. V., Magnesium, Nitrogen Codoped $\mathrm{Cr}_{2} \mathrm{O}_{3}$ : A PType Transparent Conducting Oxide. Applied Physics Letters 2011, 99, 111910-1, 111910-3. 14. Arca, E.; Fleischer, K.; Shvets, I. V., Influence of the Precursors and Chemical Composition of the Solution on the Properties of Zno Thin Films Grown by Spray Pyrolysis. J Phys Chem C 2009, 113, 21074-21081.

15. http://www.ing.unitn.it/ maud/ Http://Www.Ing.Unitn.It/ Maud/.

16. Castaldi, L.; Kurapov, D.; Reiter, A.; Shklover, V.; Patscheider, J., Tuning the Crystallographic and Electronic Properties of Chromium Oxynitride Films. J Appl Phys 2011, $109,053720$.

17. Kucheyev, S. O.; Sadigh, B.; Baumann, T. F.; Wang, Y. M.; Felter, T. E.; van Buuren, T.; Gash, A. E.; Satcher, J. J. H.; Hamza, A. V., Electronic Structure of Chromia Aerogels from Soft X-Ray Absorption Spectroscopy. J Appl Phys 2007, 101, 124315-8.

18. de Groot, F. M. F.; Grioni, M.; Fuggle, J. C.; Ghijsen, J.; Sawatzky, G. A.; Petersen, H., Oxygen 1s X-Ray-Absorption Edges of Transition-Metal Oxides. Phys. Rev. B 1989, 40, $5715-5723$.

19. MacNeil, J. H.; Zhang, H.-T.; Berseth, P.; Trogler, W. C., Catalytic Decomposition of Ammonium Nitrate in Superheated Aqueous Solutions. J Am Chem Soc 1997, 119, 97389744. 
20. Fanning, J. C., The Chemical Reduction of Nitrate in Aqueous Solution. Coordin Chem Rev 2000, 199, 159-179.

21. Zunger, A., Practical Doping Principles. Appl Phys Lett 2003, 83, 57-59. 